Linguagem em (Dis)curso, Palhoça, SC, v. 9, n. 3, p. 621-643, set./dez. 2009

\title{
CONSIDERAÇÕES SOBRE O CONCEITO DE "INTERNETÊS" NOS ESTUDOS DA LINGUAGEM*
}

\author{
Fabiana Komesu** \\ Luciani Tenani***
}

\begin{abstract}
Resumo: Nosso objetivo neste ensaio é discutir o conceito do chamado "internetês", popularmente conhecido como o português escrito (digitado) na internet. Da perspectiva dos estudos da linguagem, em particular, de teorias provenientes dos estudos do discurso, procuramos explicitar perguntas e apresentar hipóteses acerca desse fenômeno em emergência, comumente tomado como escrita "fonetizada" ou como "interferência da fala na escrita". De nosso ponto de vista, analisar o internetês permite observar uma possibilidade da língua e do discurso, considerando-se a heterogeneidade como traço constitutivo da linguagem e das atividades verbais humanas. Com base, pois, em um conjunto de dados composto de enunciados escritos, os quais seriam característicos do internetês, buscamos mostrar a relevância das definições de escrita, de língua e de linguagem para sua conceituação, levandose em conta a relação radical entre linguagem e vida social.
\end{abstract}

Palavras-chave: aquisição da escrita; letramento; oralidade; discurso; internet.

\section{INTRODUÇÃO}

Crystal (2005), na introdução de sua obra $A$ revolução da linguagem, destaca o fato de que "a maioria de nós não pensa muito sobre a língua e

\footnotetext{
* Uma versão anterior deste texto foi apresentada por Komesu na mesa-redonda "Internetês: reflexões sobre a escrita na Internet", no âmbito do II Encontro Nacional sobre Hipertexto, realizado na Universidade Federal do Ceará (UFC), de 25 a 27 de outubro de 2007.

** Professora da Universidade Estadual Paulista, São José do Rio Preto, SP, Brasil. Projeto financiado pela FAPESP (04/14887-8). Doutora em Linguística. Email: <komesu@ibilce.unesp.br>.

*** Professora da Universidade Estadual Paulista, São José do Rio Preto, SP, Brasil. Doutora em Linguística. Email: <lutenani@ibilce.unesp.br>.
} 
não está acostumada a tê-la como foco de atenção" (p. 13), ainda que acontecimentos diversos tenham colocado em evidência a questão da língua, nos últimos anos.

Em 1999, por exemplo, o linguista britânico lembra que a Organização das Nações Unidas decretou 21 de fevereiro como Dia Internacional da Língua Materna; 2001, por sua vez, foi designado o Ano Europeu das Línguas, com a celebração de todas as línguas faladas na Europa, incluídas as usadas por minorias.

No Brasil, destacamos 2006 como o ano em que foi inaugurado o Museu da Lingua Portuguesa, na cidade de São Paulo, cujo tema é a língua portuguesa. Segundo a coordenação, o objetivo do museu é "fazer com que as pessoas se surpreendam e descubram aspectos da língua que falam, lêem e escrevem, bem como da cultura do país em que vivem, nos quais nunca haviam pensado antes" 1

Refletir sobre a língua que falamos, lemos ou escrevemos não parece estar, assim, tão fora do foco de atenção. Basta observar ainda, em nossa sociedade, a proliferação de manuais de redação em língua portuguesa, vendidos em bancas de jornal; a multiplicação de programas de televisão e de rádio, que ensinam - como se essa fosse a função dos meios de comunicação - como expressar-se "com clareza" e "com correção". Há também o crescimento vertiginoso de sites especializados em assessoria sobre todo e qualquer assunto que diga respeito à língua.

Retomamos, aqui, a reflexão de Gnerre (1998) sobre linguagem e poder para pensar a questão da língua. Segundo o historiador italiano, é preciso observar que "a linguagem não é usada somente para veicular informações", ao contrário do que se poderia imaginar com a assunção da eficácia de manuais de redação e de programas midiáticos. Citando Bourdieu (1977), Gnerre adverte que "o poder da palavra é o poder de mobilizar a autoridade acumulada pelo falante e concentrá-la num ato linguístico" (GNERRE, 1998, p.5), o qual expõe, enfim, as fronteiras, os modos de negociação entre os sujeitos no jogo de representações das relações sociais.

Índice outro da atenção social voltada para a questão da língua é o espaço que tem sido destinado, cada vez com maior frequência na

\footnotetext{
${ }^{1}$ Disponível em: <http://www.museudalinguaportuguesa.org.br/>. Acesso em: 20 out. 2007.
}

KOMESU; TENANI - Considerações sobre o conceito de "internetês"... 
grande imprensa e na imprensa especializada, à discussão sobre a língua portuguesa produzida em ambiente digital, popularmente conhecida como "internetês". A Revista Veja, de 12 de setembro de 2007, por exemplo, trazia como assunto de capa Falar e escrever certo. Sob o pretexto de discutir o acordo ortográfico, a revista de maior tiragem e circulação no País apontou também para o "início de uma nova era linguística" decorrente do advento da internet e das novas tecnologias de comunicação e informação. Na imprensa especializada, a Revista Lingua Portuguesa, edição de março de 2006, destacou a "revolução do internetês" e a relação com a produção escrita, em especial, a dos jovens.

Nossa proposta neste artigo é discutir o conceito de internetês, em particular, da perspectiva dos estudos da linguagem que privilegiam teorias provenientes do discurso. Na próxima seção, apresentamos, pois, algumas considerações sobre a definição do "internetês" nos estudos da linguagem. O objetivo é explicitar perguntas e apresentar hipóteses acerca desse fenômeno da linguagem, comumente tomado como uma escrita "fonetizada" ou como "interferência da fala na escrita". De nosso ponto de vista, buscamos mostrar, mediante descrição e análise de enunciados, que se trata de uma possibilidade da língua $e$ do discurso, considerando-se a heterogeneidade como traço constitutivo da linguagem e das atividades verbais humanas.

\section{O CONCEITO DE “INTERNETÊS” NOS ESTUDOS DA LINGUAGEM}

Como já anunciado, cremos que é preciso indagar o que é "internetês" a partir da perspectiva dos estudos sobre linguagem. Para tanto, iniciamos nossa reflexão apresentando o seguinte excerto, extraído do texto de perfil de um usuário da rede social orkut: ${ }^{2}$

\section{Texto 1}

1 GENNTTIII..

\footnotetext{
2 De uma forma geral, pode-se dizer que uma rede social digital é aquela em que um indivíduo, vinculado a um sistema constituído pela interligação de dois ou mais computadores e seus periféricos, liga-se a outro indivíduo, de outra rede, com objetivo de comunicação, de compartilhamento, de intercâmbio de dados afins, resultando na criação de novos grupos na e pela internet (cf. RECUERO, 2006).
} 
2 BOUMM.

3 FALAH SOBRI EU!?!?

4 HMM.

5 EH MEIU DIFICILLL..

6 AIN AINN..

7 DXA EU PENSA..

8 BOUM..

9 GOXTO DE SAI..

10 IR IM BALADA..

11 BJA NA BOK..

12 FIKAR ENTRI AMIGUHS..

13 ODEIU IZTUDA..

14 HEHE

O internetês é conhecido como forma grafolinguística que se difundiu em textos como chats, blogs e demais redes sociais. Seria uma prática de escrita caracterizada pelo registro divergente da norma culta padrão, como pode ser verificado no Texto 1, razão pela qual seus adeptos são tomados como "assassinos da língua portuguesa", do ponto de vista dos avessos a essa prática de escrita. A prática de abreviação, o banimento da acentuação gráfica, o acréscimo ou a repetição de vogais, as modificações do registro gráfico padrão, com troca ou com omissão de letras, são alguns dos traços que podem ser observados na ortografia desse texto, os quais serão descritos e discutidos na próxima seção. É esse quadro que, apresentado ao não-iniciado, é quase sempre tomado como "simplificação da escrita", com consequente "morte da língua".

As referências bibliográficas sobre o tema são ainda escassas. É possível encontrar entrevistas em periódicos da grande imprensa (TEIXEIRA, 2007; VOLPATO, 2007) e da imprensa especializada (NOGUEIRA, 2006; MARCONATO, 2006; CONSOLARO, 2007), mas quase não há artigos acadêmicos publicados sobre o assunto (ARAÚJO, 2007; KOMESU, 2006, 2007). 
Ataliba de Castilho, por exemplo, em entrevista à Revista Lingua Portuguesa, expõe que o internetês seria "parte da metamorfose natural da língua" (apud MARCONATO, 2006). De acordo com o autor, há "redução de excessos da ortografia" na linguagem empregada na internet, uma vez que toda palavra é contextualizada pelo falante no evento de comunicação (apud MARCONATO, 2006). Bagno (apud VOLPATO, 2007), por sua vez, em entrevista à Revista da Cultura, acredita que o internetês é "questão de grafia". Para o sociolinguista, trata-se de um fenômeno que deve ser observado na complexidade das transformações sociais, culturais e tecnológicas (BAGNO apud VOLPATO, 2007). Araújo (2007) argumenta que o internetês "vai muito além de simples ocorrências vocabulares estranhas", caracterizando o que defende ser "um registro de uso da escrita", "uma variedade linguística, no sentido sociolinguístico do termo". Para Araújo, o internetês é uma "modificação criativa na escrita da língua em ambiente digital, cujas características apontam para uma linguagem alfanumérica" (ARAÚJO, 2007, p.28).

Em comum, pode-se considerar que esses autores buscam refletir sobre um conceito de internetês que não leve em conta apenas o material linguístico, mas, sim, sua relação com o que é tomado como exterior à língua, na dinâmica sócio-histórica da relação entre sujeito, linguagem e novas tecnologias de comunicação e informação. Dentre as hipóteses dos especialistas para esse tipo de grafia está o princípio do "economize uma teclada" (CRYSTAL, 2005; CASTILHO apud MARCONATTO, 2006), com consequente diminuição do tempo de escrita nas relações digitais (XAVIER apud TEXEIRA, 2007). Mas não somente: a emergência do internetês se dá mediante uma possibilidade da língua e do discurso, como buscaremos mostrar.

Destacamos ainda, dentre as reflexões de especialistas em linguagem, a de Crystal (2005) e sua investigação sobre comunicação mediada por computador ou o que denominou netspeak. Para Crystal, o netspeak é "mais do que um híbrido de fala e escrita". Trata-se, para o autor, da constituição de textos eletrônicos que demonstram fluidez, simultaneidade, não degradação material, transcendência das limitações tradicionais da disseminação do texto, além da inter-relação entre textos, facultada pelo advento do link (CRYSTAL, 2005, p. 90). Pode-se dizer que o netspeak ao qual Crystal se refere não é o "internetês", uma vez que 
o objeto de estudo do autor é a língua inglesa e não o português brasileiro. No entanto, a utilização de técnicas de rébus, de abreviações ou de indicações fonéticas guarda estreita relação com o que é observado em língua portuguesa (CRYSTAL, 2005, p. 91-92).

Com efeito, o reconhecimento - ou o não reconhecimento - de determinadas práticas de escrita na rede leva os sujeitos a projetarem, em particular no senso comum, a imagem de "transformação" da língua(gem), com consequente "degradação" (e/ou "morte") da língua. Trata-se de preocupação legítima, se se considerar o ineditismo do tema e a inserção do tema em campos de saber como as Ciências da Linguagem, a Comunicação Social e a Educação (em especial a de crianças e de jovens), por exemplo. Ressaltamos que essa visão apreciativa (depreciativa) que concebe a escrita na rede como escrita "fonetizada" ou como "transcrição", "influência", "interferência" da fala na escrita não se restringe, porém, ao território brasileiro. Crystal (2005) assinala, no cenário anglófono, o temor sentido por observadores que consideram o netspeak uma "deterioração de padrões" da "regras tradicionais da língua escrita”. Na França, Ladjali (2007) critica o suposto "barbarismo" instaurado mediante o advento de práticas de escrita relacionadas a novos suportes, como o computador e o aparelho celular. Para o que nos interessa, os estudos em linguagem podem contribuir para a problematização do fenômeno do internetês no âmbito de uma avaliação distinta do da desqualificadora.

Fundamentamo-nos, pois, na proposta de Corrêa (2004) sobre a heterogeneidade constitutiva da escrita para propor essa reflexão. Em trabalho anterior (KOMESU; TENANI, s/d), buscamos colocar em evidência a necessidade de recusa a uma noção corrente de escrita, com aproximação a uma noção outra para pensar a escrita em contexto digital. A noção primeira que recusamos é a que concebe escrita como modalidade da língua, fundada no aspecto estritamente semiótico. Dada a suposta fixidez no plano, à apreensão visual, os adeptos dessa noção de escrita concebemna em oposição à fala, numa relação marcada por dicotomias estritas (cf. críticas de KOCH, 2003; MARCUSCHI, 2004; CORRÊA, 2004).

Consideramos que é a partir de um critério de pureza projetado como ideal da modalidade escrita que muitos fazem a crítica aos usos que emergem da internet. A imagem de degradação da escrita e, por extensão, a da língua, pelo uso da tecnologia digital, advém do 
pressuposto de que haveria uma modalidade escrita pura, associada seja à norma culta padrão, seja à gramática, seja à imagem de seu uso por autores literários consagrados; enfim, um tipo de escrita sem "influências" ou "interferências" da fala, que deveria ser seguido por todos em quaisquer circunstâncias. Há, portanto, a presunção de um sistema abstrato de formas linguísticas destituído da expressão dos modos de interação e de sua relação com a sociedade, com a história, com a cultura.

A segunda noção de escrita, proposta por Corrêa (2004), é a que assumimos em nosso trabalho. Trata-se de um modo de enunciação fundado no encontro entre práticas sociais do oral/falado e do letrado/escrito, considerada a dialogia com o já falado/escrito e ouvido/lido. Corrêa apóia-se no princípio dialógico da linguagem, de Bakhtin (1997), para propor que, no processo da escrita, o escrevente circula por um imaginário socialmente partilhado sobre a língua em suas diversas manifestações e variedades, imaginário que se particulariza para as situações específicas e concretas do uso da escrita e que se estende aos diferentes e instáveis modos de conceber a relação escrita/mundo e escrita/fala. No âmbito dessa proposta teórico-metodológica de Corrêa, pode-se observar "as relações reais entre os agentes sociais e a escrita, consideradas as práticas sociais de que, direta ou indiretamente, a escrita

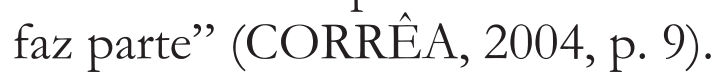

A proposição de um modo heterogêneo de constituição da escrita - e não de uma heterogeneidade na escrita - permite que se volte a atenção ao processo de produção do enunciado, com seu valor de acontecimento social e histórico, e não somente ao aspecto estrutural de um produto escrito. A visão tradicional da relação fala/escrita pressupõe a interferência da fala na escrita, com a assunção preconceituosa contra as práticas orais/faladas. Mais do que isso, a assunção dessa perspectiva desconsidera o fato de que o modo da existência da língua encontra-se na comunicação discursiva concreta, isto é, na diversidade dos gêneros do discurso que compõem as esferas de atividade humana (BAKHTIN, 1997).

No caso específico do "internetês", é preciso discutir, no âmbito dos estudos da linguagem, que não se trata $\boldsymbol{d a}$ língua portuguesa escrita na internet ou de sua degeneração, mediante "interferência da fala na escrita". Trata-se de uma (ou de algumas) possibilidade(s) da língua, 
considerando-se os propósitos de comunicação dos sujeitos na linguagem. Desse modo, com base na concepção de modo de enunciação da escrita, os registros divergentes encontrados nos enunciados na internet passam a ser associados às possibilidades de registro gráfico-visual de certos padrões rítmico-entoacionais que são assim registrados pelo sujeito na heterogeneidade da escrita, na interação com o(s) outro(s) (CHACON, 1998; TENANI, 2007). A assunção da tese da heterogeneidade permite ao analista justificar a presença de fatos linguísticos da enunciação falada na enunciação escrita. É preciso, ainda, pensar que a presença desses fatos linguísticos da fala na escrita produzida no contexto da tecnologia digital representa a identidade de um grupo ou de uma comunidade que quer se reconhecer por elas e por elas ser reconhecido.

Nossa proposta, portanto, para a investigação da relação entre fala e escrita em enunciados produzidos em contexto digital - mas não somente - é explicitar perguntas e apresentar hipóteses acerca desse fenômeno da linguagem, com base em teorias discursivas que privilegiem a associação radical entre língua $e$ discurso, como procuramos discutir na próxima seção.

\section{3 "ESCRITA FONETIZADA": DISCUSSÃO SOBRE DADOS DO INTERNETÊS}

Voltemos ao texto apresentado na seção anterior. O que aconteceria se o usuário da internet fosse capaz de observar, com o auxílio de uma teoria científica, certa regularidade linguística constitutiva daquela atividade verbal? Ou ainda, o que diria um investigador da linguagem escrita se tomasse o Texto 1 daqui há 500 anos, supondo que the restassem poucas informações explícitas sobre o modo de funcionamento do internetês? Diria esse investigador que se trata de uma escrita com "interferência da fala"?

Assumindo a posição de um investigador que toma como ponto de partida as normas ortográficas vigentes para a escrita do Português no Brasil, saltam aos olhos que várias são as "infrações” às normas! Apenas no que diz respeito à ortografia das palavras, identificam-se omissão, 
acréscimo ou troca de letras, uso não-convencional de maiúsculas, omissão de acento e til, por exemplo. Estariam essas "infrações ortográficas" ancoradas em uma relação entre fala e escrita de tal modo que a escrita teria se transformado em "fonetizada"? Exploraremos essa hipótese, mostrando, em primeiro lugar, em que medida ela se sustenta e, em segundo lugar, em que medida ela não se sustenta. Argumentaremos, a partir desse exercício de análise da escrita de um texto tomado como um exemplo do internetês, que a não observação das convenções ortográficas não implica dizer que essa escrita é o lugar do caos ou é a não lingua, não sistematizada.

Tomamos como ponto de partida de análise as ocorrências "HMM", "AIN", "AINN", "HEHE". Todos esses elementos nãolexicalizados não são palavras do Português, mas podem ser reconhecidas como possíveis representações de sequências fônicas que ocorrem em situação de interação face a face ${ }_{s}$ características de enunciados falados. Recuperando o texto em que ocorrem essas sequências, pode-se afirmar que:

a) "HMM" poder ser uma "correção auto-iniciada feita no mesmo turno" (MARCUSCHI, 1986, p. 28 ss.), a qual sinaliza ao interlocutor uma reelaboração do dizer e, simultaneamente, visa assegurar o turno na interação;

b) "AIN", "AINN": poder ser, também, uma técnica de correção que sinaliza ao interlocutor uma reelaboração do dizer, mas, diferentemente da ocorrência anterior, pode-se reconhecer "ai" como uma palavra em Português, seguida de um som nasal (representado por "N"). Somado o fato de haver repetição da mesma sequência gráfica "AIN", pode-se interpretar essas sequências como tentativas de representação de uma elaboração difícil (daí o uso de "ai" para algo "doloroso"), que diz respeito a uma "auto-análise" na presença do outro (temática do texto em questão). Assim como outras técnicas para iniciação de correções na enunciação falada, as ocorrências analisadas visam assegurar o turno na interação;

c) "HEHE" é uma das formas de representar os sons produzidos em uma risada, o que pode ser visto como uma forma de 
estabelecer a interação com o possível leitor/interlocutor (KOMESU, 2002).

A afirmação de ser o internetês uma escrita "fonetizada" não está baseada apenas nas ocorrências anteriormente descritas e inclui, também, o emprego das letras a partir de uma suposta relação biunívoca entre letra-som, seguindo o princípio acrofônico do alfabeto e não as regras ortográficas. Estão em jogo, portanto, quer uma concepção da relação fala e escrita, quer o trânsito do escrevente pelo sistema de escrita alfabético e pelas convenções ortográficas em uso para o Português. É preciso, ainda, destacar a situação de comunicação na qual o Texto 1 emerge. Trata-se de apresentação pessoal em nível informal, em que um usuário da rede expõe certa imagem de si a um grupo cujo interesse, dentre outros, é conhecer "novas pessoas através de amigos de seus amigos e comunidades", para a partilha de "paixões" em comum, como pode ser verificado no texto da página principal do site da rede social em questão. ${ }^{3}$ Passemos, pois, a explicitar como se dão essas relações entre fala e escrita, a partir do texto selecionado para análise.

As grafias de "GENNTTIII", "BOUMM", "DIFICILLL" têm em comum a repetição de algumas letras (predominantemente aquelas que estão em fim de sílaba, a saber: "N", "I", "M" e "L"). Essa repetição pode ser interpretada como uma tentativa de reprodução da duração dos segmentos por essas letras representadas. Nota-se que essas repetições também não ocorrem de forma aleatória, se considerada a organização textual: "GENNTIIII" e "BOUMM" (linhas 1 e 2) constituem-se em dois enunciados (a mudança de linha pode ser tomada como evidência dessa análise) que são característicos da tomada do turno pelo interlocutor em início de interação. Também são encontrados nesses enunciados - que seriam falados, se lidos em voz alta - alongamentos de vogal ou de consoantes em final de sílaba.

Além da duração, a transcrição da realização de alguns segmentos tais como ocorrem em enunciados falados motiva a troca de letras, de modo que se observam trocas (onde sublinhado) de "I" no lugar de "E", como em "SOBRI", "IM", "ENTRI", "IZTUDA", ou de "U" no lugar

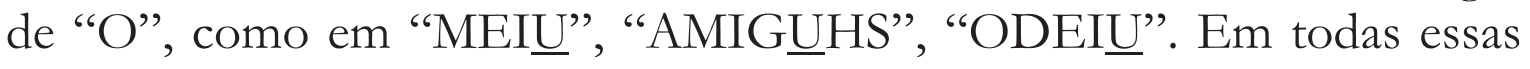

${ }^{3}$ Disponível em: <http://www.orkut.com>

KOMESU; TENANI - Considerações sobre o conceito de “internetês"... 
ocorrências houve alçamento vocálico, um processo fonológico em que as vogais médias /e/ e /o/ passam a ser vogais altas, respectivamente, [i] e $[\mathrm{u}] .{ }^{4}$ Lembramos que, segundo as convenções ortográficas, as letras "E" e "O" podem representar tanto as vogais médias altas [e] e [o], respectivamente (como em "l[e]tra" e "v[o]gal"), quanto as vogais médias baixas $[\mathrm{E}]$ e $[\mathrm{O}],{ }^{5}$ respectivamente (como em "r[E]to" e "r $[\mathrm{O}] \mathrm{ta}$ "), como ainda as vogais altas [i] e [u], respectivamente (como em "b[i]zerr[u]"). Nas ocorrências ora analisadas, o emprego das letras " $E$ " e "O" não segue as convenções ortográficas e, sim, as realizações na enunciação falada. Dessa forma, esse emprego das letras corrobora a afirmação de que a escrita na internet seria "fonetizada". Cabe destacar que esse emprego nem sempre ocorreu no texto selecionado, de modo que "GOXTQ O" e "DE" (linha 9) são grafadas segundo as convenções ortográficas no que diz respeito ao emprego das letras "O" e "E", embora na fala ocorram as vogais [u] e [i], respectivamente: "gost[u] d[i]".

Uma outra evidência que favorece a visão de o internetês ser caracterizado por uma escrita "fonetizada" pode ser dada com base na grafia de "BO్M", a qual apresenta acréscimo de uma letra em relação à forma ortográfica. Esse acréscimo de letra é motivado pela ditongação que ocorre em sílabas tônicas quando há vogais médias altas seguidas por consoantes nasais em posição de fim de sílaba, como em "bo[u]m", "avo[u]m", "se [i]m" e "se[i]mpre". Nota-se mais uma vez que, no texto em análise, nem sempre a ditongação é representada - embora as palavras, se lidas em voz alta, sofram ditongação - como em "PENSA" (linha 7) e "ENTRI" (linha 12), que se realizam, respectivamente, como "pe[i]nsar" e "e[i]ntre".

Diferentemente das grafias ora descritas, há um outro conjunto de grafias que se caracterizam por apresentar omissão de letras em relação às convenções ortográficas, como em: "DXA", "PENSA

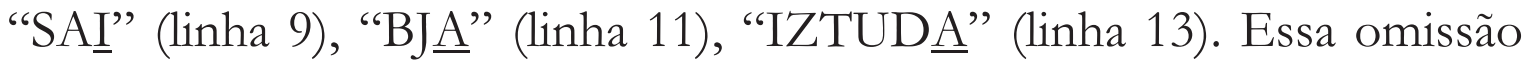

\footnotetext{
4 Estudos sobre o alçamento vocálico mostram haver contextos fonológicos específicos que propiciam esse processo. No entanto, é tema de debate entre os pesquisadores uma descrição de todos os fatores que desencadeiam esse processo nas diferentes variedades do Português no Brasil (cf. BISOL, 1981; VIEGAS, 1987; LEE; OLIVEIRA, 2003; TENANI; SILVEIRA, 2008).

${ }^{5}$ Utilizamos as letras maiúsculas para representar as vogais médias abertas por não ser previsto $\mathrm{O}$ emprego das fontes do IPA, com os símbolos estabelecidos para esses sons pela Associação Internacional de Fonética.
} 
tem sua principal motivação no fato de haver, em enunciados falados, processos fonológicos que resultam em apagamento de segmentos. $\mathrm{Na}$ lista de palavras anteriormente elencadas, não foi escrita a letra " $R$ " a qual indica o morfema de infinitivo das formas verbais (a saber: "deixar", "pensar", "sair", "beijar", "estudar"). 6 Assim, um princípio dessa escrita "fonetizada" seria "o que não é falado não é escrito", ou, em uma formulação mais geral: "escreve-se o que se fala". Esse princípio levaria, por um lado, à omissão de letras, quando não se realizam segmentos, e, por outro lado, ao acréscimo de letras, quando há inserção de segmentos na fala. A escrita seria, portanto, uma representação "fiel" da fala, o que sustentaria a afirmação de ser o internetês uma escrita "fonetizada". No entanto, essa afirmação torna-se frágil se considerarmos as omissões de letras que não têm sua motivação na fala, como em: "ㅁJA", "BOK $\underline{K}$ " (linha 11), "DXXA" (linha 7). Nos três exemplos ora apresentados, a omissão de letra - que representa a vogal - é baseada no nome da letra consonantal em Português. Assim, substituindo o nome das letras "B", "K" e "D" - que são "bê", "ka", "dê" - nas palavras dadas, temos: "BEJA", "BOKA" e "DEXA". Nota-se que, em Português, há um conjunto das letras que representam consoantes as quais são nomeadas com o acréscimo de uma vogal (geralmente a vogal "E"), de modo que se obtém uma sílaba (como também é o caso de: "C", "cê"; "G", "ge"; "P”, "pê"; “T”, "tê", "V”, "vê", “Z”, “zê"). ${ }^{7}$ Salientamos que o princípio que orienta a escrita dessas palavras em internetês não é de ordem fonética (portanto, não é baseada exclusivamente na fala), mas se caracteriza por um domínio sobre o sistema de escrita usado em determinadas atividades verbais. Dito de outra forma, essa escrita implica práticas letradas/escritas, não necessariamente circunscritas ao ambiente da internet.

Ainda sobre a grafia de formas nominais do verbo, particularmente sobre o " $R$ " das formas do infinitivo verbal, vale contrapor as formas já analisadas às seguintes ocorrências: "IR" (linha 10), "FIKAR" (linha 12) e "FALAH" (linha 3). Primeiramente, consideramos as grafias de "IR" e "FIKAR": ambas são grafias que

\footnotetext{
${ }^{6}$ Estudos fonológicos mostram o quanto é frequente o cancelamento (ou apagamento) desse morfema verbal em diversas variedades do Português (cf. DA HORA; MONARETTO, 2003; OLIVEIRA, 1997; CALLOU; LEITE; MORAES, 1996).

${ }^{7}$ Vale dizer que os nomes das letras remontam à história do alfabeto (cf. SAMPSON, 1996).
}

KOMESU; TENANI - Considerações sobre o conceito de "internetês"... 
seguem as convenções ortográficas, quanto à colocação do " $R$ ", morfema de infinitivo. A questão a fazer é: por que apenas essas duas ocorrências de formas de infinitivo verbal são grafadas com "R"? Um incauto observador poderia dizer que se trata de uma variação típica do internetês, uma escrita caótica. Nossa hipótese para a presença do "R" nesses casos está baseada no fato de a palavra seguinte a essas formas ser iniciada por vogal (cf. linha 10, "IR IM BALADA"; linha 12, "FIKAR ENTRI AMIGUHS"). Nos enunciados falados, ocorre um processo de juntura entre palavras de modo que, quando uma palavra termina por consoante e a seguinte se inicia por vogal, há uma reorganização das sílabas envolvidas com produção de uma nova sílaba (por exemplo: IR.IM > I.RIM). Nossa hipótese é, pois, que esse processo de juntura entre palavras (ou sândi externo) na enunciação falada tenha motivado a presença da letra "R" na enunciação escrita. Sinalizamos, pois, para uma relação entre fala e escrita que não é da ordem da representação dos sons (como supostamente se faria em uma escrita baseada na fonética), mas é uma relação que se dá a partir de hipóteses (não-conscientes) do escrevente sobre a organização dos enunciados falados e escritos constituídos de modo heterogêneo na língua(gem). Essa relação complexa também pode ser observada com base na análise de "FALAH", que pode ser caracterizada, em um primeiro olhar, por uma grafia não-convencional por haver troca de "R" por " $H$ ". A partir de um olhar mais atento, o investigador da linguagem deverá observar que: (i) "H" é frequentemente usado, em internetês, para indicar vogal acentuada, como em "EH"; 8 (ii) a forma verbal no infinitivo pode ser escrita como "falá", quando o escrevente deseja indicar a não-realização do morfema de infinitivo. Da relação entre (i) e (ii), o observador concluirá que "FALAH" é a grafia para "falá"” e, dessa maneira, não se trata de uma troca entre "R" (previsto pelas convenções ortográficas) e

${ }^{8}$ É importante lembrar que o uso do "H" para representar acento se origina no fato de o teclado, em um primeiro momento, não ser configurado para se grafarem vogais acentuadas conforme a ortografia do Português. A solução dada pelos usuários brasileiros, por exemplo, foi empregar o "H" para indicar o acento (e assim, fazendo a distinção entre "e" e "é", grafado como "eh"). Com o avanço da tecnologia, não se faz mais necessário esse uso de "H". No entanto, essa prática permanece reconhecida como característica da escrita no computador e na internet.

9 Vale lembrar que a prática de acentuar a vogal da forma de infinitivo verbal não é exclusiva da internet. Um exemplo é a grafia usada em gibis do Chico Bento, personagem do brasileiro Maurício de Sousa: Chico Bento: "Mãe... impresta o lampião?”; Mãe: "Pra mor di quê?”; Chico Bento: “Ara, pra catá cenora, uai!" (SOUSA, M. Chico Bento, n. 14, fev. 2008). 


\section{4}

"H" (usado no internetês). Portanto, da análise das várias grafias para as formas de infinitivo, pode-se concluir que o internetês se caracteriza fortemente por práticas sociais de uma escrita historicamente constituída.

Por fim, analisamos as ocorrências "GOXXTO" (linha 9) e "IZTUDA" (linha 13), especificamente no que diz respeito às trocas de letras: "X" no lugar de "S", em "GOXTO", e "Z" no lugar de "S" em "IZTUDA". Inicialmente, verifica-se que, em ambos os casos, a convenção prevê a letra "S" que pode ser realizada como uma fricativa alveolar desvozeada, em variedades como a paulista ("go[s]to"; "e[s]tudar"), ou como uma fricativa alveopalatal desvozeada, em variedades como a carioca ("go[S]to"; "e[S]tudar"). ${ }^{10}$ A partir desse fato, há uma primeira constatação: o emprego de "X" em "GOXTO" pode ser interpretado como uma possível representação da fricativa alveopalatal desvozeada, indiciando uma realização semelhante àquela de variedades cariocas. Essa interpretação está ancorada no fato de, na ortografia do Português, a letra " $\mathrm{X}$ " representar (entre outros sons) essa fricativa alveopalatal, como é o caso em "xícara", "Xuxa". A troca de "X" no lugar de "S" teria sido motivada por uma tentativa de aproximar a escrita da fala, particularmente de uma variedade linguística. Outra possibilidade de interpretação para o emprego de "X" está no fato de as crianças, em fase inicial de aquisição da linguagem (por volta de 2-3 anos) realizarem a fricativa alveopalatal no lugar da alveolar, como "[S]eu", para "céu", ou ainda "go[S]to". Poderia supor, dessa perspectiva, que se trata de uma escrita baseada em uma representação de uma fala infantil, pois, no Brasil, características dos enunciados infantis estão associadas à apresentadora de programa infantil Xuxa, que não apenas tem em seu nome a fricativa alveopalatal e é falante da variedade carioca, como também produz enunciados em que faz trocas entre as fricativas alveopalatais e alveolares em contextos típicos daqueles observados em enunciados de crianças em fase inicial da aquisição da linguagem. Ainda há uma outra constatação a fazer sobre o emprego de "Z" em "IZTUDA": não há motivação para esse emprego de " $Z$ " em nenhuma das possibilidades de realização (independentemente da variedade linguística a ser considerada), pois " $Z$ " representa, na ortografia do Português, uma fricativa alveolar vozeada e

${ }^{10}$ Estamos empregando $[\mathrm{S}]$ para indicar a fricativa alveopalatal desvozeada.

KOMESU; TENANI - Considerações sobre o conceito de "internetês"... 
esse som não ocorre no contexto de fim de sílaba em "estudar", pois se trata de um ambiente desvozeado (e que, portanto, só permitirá a ocorrência de uma fricativa desvozeada, seja ela alveolar ou alveopalatal). ${ }^{11}$ Dessa análise, conclui-se que o emprego de " $Z$ " em "IZTUDA" não tem motivação em uma relação de proximidade entre enunciados falados e escritos. A motivação para essa grafia pode ser encontrada se considerado o enunciado em que ocorre: "ODEIU IZTUDA" (linha 13). O emprego de "Z", nessa palavra, pode ser visto como um "erro" ortográfico que dialoga com o conteúdo semântico de "estudar" e que faz ecoar um enunciado já falado/ouvido: "quem não estuda, escreve errado"! Essa análise ganha força se considerarmos que, em seguida, o escrevente conclui seu texto com uma "risada", "HE, HE" (linha 14), que pretende ganhar a cumplicidade do interlocutor no que diz respeito à grafia que emprega. Concluímos que a grafia de "IZTUDA" oferece argumentos a favor de uma visão do internetês como uma escrita que traz marcas da dialogia com o já falado/escrito e ouvido/lido.

Levando-se em conta essa visão dialógica da linguagem, retomamos a ocorrência "GOXTO" para analisar o emprego de "X" não apenas como representação de uma possível realização fônica da palavra, mas também como elemento que faz reverberar enunciados associados a imagens daqueles que infringem as normas (no caso, as ortográficas). Trazemos para essa discussão o texto, abaixo transcrito, de uma propaganda do refrigerante Sprite, veiculada na revista Superinteressante (edição 244, nov. 2007), a qual se caracteriza por uma grafia nãoconvencional que seria típica do internetês.

\section{Texto 2}

GERALW

XCREVI AXIM

SOH PRA

DIXAVAR

\footnotetext{
${ }^{11}$ Cabe observar que é possível que a troca de "z" no lugar do "s" tome por base a realização fônica em contextos de fim de sílaba quando for possível o processo de vozeamento da fricativa de modo que à letra "s" corresponderia o som [z], como em "me[z]mo".
} 


\section{UX ERRUX.}

\section{XPRAIT. AX COISAX KOMU SAUM.}

Entre as hipóteses explicativas para a grafia empregada no texto, que possam ser relevantes para a análise da propaganda, destacamos a que se relaciona ao emprego de "X". No Texto 2, substitui-se "X" pela letra "S" (como em "UX ERRUX" para "os erros"), ou pelo dígrafo "SS" (como em "AXIM" para "assim"), ou ainda pelo dígrafo "CH" (como em "DIXAVAR" para "dichavar"). ${ }^{12}$ Da análise do texto identificam-se, entre vários enunciados possíveis, um que diz respeito à escrita que seria caracterizada por erros de ortografia. Salienta-se que há blogs cuja temática é a discussão sobre o uso (indesejável) dessa grafia nessa propaganda, avaliando-a como indício de decadência cultural e linguística, como se constata dos textos que seguem ${ }^{13}$ (acessados em 25 nov. 2008).

\section{Texto 3}

Pela Meleca Sagrada de Cristo, quem aprova uma coisa dessas? Pior, quem ESCREVE um anúncio desses? Meu amigo, me desculpe, mas não dá pra se dizer REDATOR com um anúncio assim. Você não redigiu nada, no máximo regurgitou. Desligou o cérebro, deixou ligados somente os neurônios mínimos para sua sobrevivência, e em um momento de folga deles cuspiu essa obra de arte.

\footnotetext{
12 Para "DIXAVAR", também se encontram comentários em sites que pretendem definir o significado do verbo, os quais, predominantemente, afirmam que se trata de "disfarçar", "esconder" ou ainda de "gíria de maconheiro" para nomear o processo de esmiuçar o "tijolo" de maconha. De uma perspectiva discursiva, interessa-nos destacar que se trata de campanha publicitária que foi veiculada uma única vez na Revista Superinteressante, naquele ano, justamente, na edição que tinha como capa a temática da descriminalização e legalização das drogas (álcool, entorpecentes em geral) no Brasil, com função explícita de acabar com o ciclo de tráfico e de violência na sociedade. Em termos de seu funcionamento implícito, pode-se dizer que a publicidade do refrigerante Sprite apresentava como leitor-modelo o sujeito afeito à prática de "dixavar" drogas. Esta seria uma explicação para as queixas daqueles que não conseguiram (não puderam) ler a ironia da propaganda. Ainda de um ponto de vista discursivo, poder-se-ia dizer que os responsáveis pela campanha apresentam uma associação entre "escrita não convencional" (na internet) e "droga", uma vez que quem escreve do modo apresentado no Texto 2 buscaria "dixavar ux errux".

${ }_{13}$ Disponíveis em < http://www.contraditorium.com/2007/12/03/et-tu-coca-cola/>
}

KOMESU; TENANI - Considerações sobre o conceito de "internetês"... 
Eu, que não leio e nem escrevo nesta linguagem (se é que se pode chamar isto de linguagem), tive dificuldades para entender o texto. A Coca-Cola parece que ignorou o fato de que neste país ainda se fala - e se escreve, em Português. (G.N., 03/12/2007)

\section{Texto 4}

O que raios quer dizer dixavar? Deve ser o primeiro caso de analfabeto até em miguxês. (J.N., 03/12/2007)

\section{Texto 5}

Dentro do contexto da propaganda (Leiam as palavras no pé da página) acho perfeitamente válida a propaganda. Sim, tal como o Q., acho que há uma ironia maior nesta propaganda, que nada mais mostra do que a realidade de pessoas que se comunicam através de uma sub-linguagem como forma de esconder os erros gramaticais e ortográficos. Infelizmente as coisas são assim, e uma crítica bem humorada aos que escrevem desta maneira talvez não seja de todo o mal (Lugar comum: É rindo que se corrigem os vícios), mesmo que o criador da campanha tenha que desligar seu lobo frontal momentaneamente. (P., 04/12/2007)

\section{Texto 6}

Novamente: que ironia? Eu perdi e muito a ironia. A única coisa que se assemelha a ironia é a relação entre o slogan "Sprite: as coisas como são" e o texto da campanha. O problema pra mim é que o texto é ininteligível pra alguém que leia uma revista; "dixavar" não parece em quase nada com "disfarçar" (se é que é realmente o que significa), poderia ser até "deslavar" e ninguém notaria a diferença. (B.G., 04/12/2007)

Os excertos arrolados têm a modalidade escrita como foco de atenção e se posicionam a favor de uma escrita ortográfica conforme aquela prescrita pelas convenções, contra o chamado internetês por avaliarem-no como não sendo Português - seria uma sub-linguagem, não se pode chamar isto de linguagem; trata-se de prática de "analfabeto"... Partidários ou avessos a essa prática de escrita poderiam ainda classificar os Textos 1 e 2 como "miguxês", como aponta o escrevente no Texto 4, por, dentre outros aspectos, empregar de maneira exacerbada o " $\mathrm{X}$ " no processo de composição das palavras. Mais do que questões estritamente linguísticas, procuramos salientar que os comentadores não especialistas 
em linguagem consideram questões definidas como "extralinguísticas" para a realização dessa prática, como o fato de o escrevente virtual ser tomado, por exemplo, como criança ou adolescente (é um "baixinho" da Xuxa) e/ou vinculado a certo grupo social (patricinhas, emos, analfabetos, doentes mentais, homossexuais). Estamos de acordo com Maingueneau (2005), para quem "o discurso não deve ser pensado somente como um conjunto de textos, mas como uma prática discursiva" (MAINGUENEAU, 2005, p. 23 [grifos no original]) a qual implica determinado modo de enunciação reconhecido na sociedade, na relação entre os sujeitos, entre os discursos. No caso específico do Texto 1, ao grafar "GOXTO", o escrevente aproxima-se daqueles que tomam o internetês como uma possibilidade de "liberdade", um lugar para infringir normas, e distancia-se daqueles que defendem o emprego das normas ortográficas. Estão em confronto, portanto, pelo menos duas práticas sociais relacionadas à escrita.

\section{CONSIDERAÇÕES FINAIS}

Concluímos a seção anterior tendo explicitadas hipóteses para: (i) a repetição de letras (cf. "DIFICILLL"); (ii) a troca de letras (cf. "SOBRI’”); (iii) o acréscimo de letras (cf. "BOLUM"); e (iv) a omissão de letras (cf. "ㅌJA"). Analisamos os aspectos ortográficos do internetês a fim de mostrar a complexidade que o caracteriza e de refutar a afirmação segundo a qual seria uma escrita "fonetizada". Apresentamos, também, argumentos que sustentam - com base na contraposição entre $O$ funcionamento das grafias não-convencionais no internetês e a das convenções ortográficas - que, por exemplo, as grafias de "GOXTO" e "IZTUDA" são motivadas em possibilidades da língua $e$ do discurso, concomitantemente.

Com efeito, a investigação do conceito de internetês coloca em evidência diferentes modos de percepção que o sujeito - usuário ou não da rede, especialista ou desconhecedor de teorias da linguagem - tem da atividade de escrita do internetês e de determinada concepção de língua. Dentre os avessos a essa prática de escrita, a noção imperativa de língua parece ser a de um instrumento de comunicaşão, segundo a qual a língua seria 
um código, capaz de transmitir ao receptor certa mensagem (GERALDI, 2004; GUIMARÃES, 2006). Esse código, concebido como um conjunto de signos que se combinam de acordo com regras, seria imutável e inequívoco, sendo comumente associado à modalidade escrita culta padrão da língua. Acreditamos que é a partir desse critério de pureza projetada como ideal da escrita que muitos indivíduos fazem a crítica ao internetês, tomando-o como um tipo de escrita sem "interferências da fala", que deveria ser seguido por todos, em quaisquer circunstâncias.

Dentre os adeptos do internetês, a noção de língua parecer ser a da forma de interação social e histórica. Mais do que possibilitar transmissão de informação ou de prometer transparência na comunicação, por meio da língua em funcionamento o sujeito dialoga com o outro, constituindose como sujeito da linguagem. Essa visão, privilegiada nos estudos enunciativos e discursivos, demanda o exame da situação de comunicação e do modo de interação entre os sujeitos na atividade verbal, o que esperamos ter colocado em evidência.

Enfatizamos, pois, que a assunção da tese da heterogeneidade da escrita implica uma noção de escrita, de língua e de linguagem constituídos dialogicamente, mediante as relações entre os sujeitos e os suportes multimodais. Cremos que as práticas de escrita na rede nos levam a afirmar que, no internetês, tem-se um lócus privilegiado de observação da escrita como um modo de enunciação fundado no encontro entre práticas sociais do oral/falado e do letrado/escrito, conforme propôs Corrêa (2004).

\section{REFERÊNCIAS}

ARAÚJO, J. C. O internetês não é língua portuguesa? Vida e educação, ano 4, n. 13, p. 28-29, mar./abr. 2007.

BAKHTIN, M. Estética da criação verbal. 2. ed. São Paulo: Martins Fontes, [1953] 1997.

BISOL, L. Harmonização vocálica: uma regra variável. 1981. 280f. Tese (Doutorado em Linguística) - Rio de Janeiro: Universidade Federal do Rio de Janeiro, 1981. 
CALLOU, D.; LEITE, Y.; MORAES, J. A. Variação e diferenciação dialetal: a pronúncia do /r/ no português do Brasil. In: KOCH, I. G. V. (Org.).

Gramática do português falado. V. 6. Campinas: Editora da Unicamp, Fapesp, 1996. p. 465-493.

CHACON, L. Ritmo da escrita: uma organização do heterogêneo da linguagem. São Paulo: Martins Fontes, 1998.

CONSOLARO, H. Entre o português e o internetês. Disponível em: <http://www.portrasdasletras.com.br/>. Acesso em: 16 out. 2007.

CORRÊEA, M. L.G. O modo heterogêneo de constituição da escrita. São Paulo: Martins Fontes, 2004.

CRYSTAL, D. A revolução da linguagem. Tradução de Ricardo Quintana. Rio de Janeiro: Jorge Zahar, 2005.

DA HORA, D.; MONARETTO, V. N. Enfraquecimento e apagamento de róticos. In:__ _ COLLISCHONN, G. (Orgs.). Teoria linguística:

fonologia e outros temas. João Pessoa: Editora Universitária da UFPB, 2003. p. 114-143.

GERALDI, J. W. Concepções de linguagem e ensino de português. In:

(Org.). O texto na sala de aula. 3. ed. São Paulo: Ática, 2004. p. 39-46.

GNERRE, M. Linguagem, escrita e poder. 4. ed. São Paulo: Martins Fontes, 1998.

GUIMARÃES, E. Os estudos sobre linguagens: uma história das ideias.

2001. Disponível em: <http://www.comciencia.br/reportagens/

linguagem/ling14.htm>. Acesso em: 21 maio 2006.

KOCH, I. G. V. A inter-ação pela linguagem. 8. ed. São Paulo: Contexto, 2003.

KOMESU, F. A modalidade escrita nas páginas eletrônicas pessoais da internet: o uso de emoticons e de "risadinhas". Sínteses, Campinas, SP, v. 7, p. 167-180, 2002.

Visões da língua(gem) em comentários sobre Internetês não é Língua

Portuguesa. Revista Filologia e Linguística Portuguesa, Universidade de São Paulo, n. 08, p. 425-437, 2006.

O bom português na internet. Vida e educação, ano 4, n. 13, p. 29, mar./abr. 2007. 
; TENANI, L. A relação fala/escrita em dados produzidos em contexto digital. Scripta, Belo Horizonte: PUC-Minas, [previsto para 2009].

LADJALI, C. Mauvaise langue. Paris: Seuil, 2007.

LEE, S. -H.; OLIVEIRA, M. A. de. Variação inter- e intra-dialetal no português brasileiro: um problema para a teoria fonológica. In: HORA, D. O.;

COLLISCHONN, G. (Orgs.). Teoria linguística: fonologia e outros temas. João Pessoa: Ed. Universitária da UFPB, 2003. p. 67-91.

MAINGUENEAU, D. Gênese dos discursos. Tradução de Sírio Possenti. Curitiba, PR: Criar Edições, 2005.

MARCONATO, S. A revolução do internetês. Revista Língua Portuguesa, v. 1, n. 5, 2006.

MARCUSCHI, L. A. Análise da conversação. São Paulo: Ática, 1986.

- Gêneros textuais emergentes no contexto da tecnologia digital. In:

; XAVIER, A. C. (Orgs.). Hipertexto e gêneros digitais. 1 ed. Rio de Janeiro: Editora Lucerna, 2004. p. 13-67.

NOGUEIRA, S. O internetês. Disponível em: <http://g1.globo.com/ Noticias/Co-lunas/>. Acesso em: 06 nov. 2006.

OLIVEIRA, M. A. Reanalisando o processo de cancelamento do (R) em final de sílaba. Revista de Estudos da linguagem, Belo Horizonte, v. 6, n. 2, p. 70-97, 1997.

RECUERO, R. C. Teoria das redes sociais e redes sociais na internet: considerações sobre o Orkut, os weblogs e os fotologs. Disponível em: $<$ http://www.rits.org.br/redes_teste/rd_tmes_jun2005.cfm>. Acesso em: 26 jul. 2006.

SAMPSON, G. O alfabeto greco-latino. In: Sistemas de Escrita: tipologia, história, psicologia. São Paulo: Ática, 1996. p.105-127.

TENANI, L. E. Reflexões sobre a ortografia usada na internet. Minicurso apresentado na IV Semana de Pedagogia, Instituto de Biociências, Letras e Ciências Exatas, Universidade Estadual Paulista Júlio de Mesquita Filho, out. 2007.

; SILVEIRA, A. A. M. O alçamento das vogais médias na variedade culta do noroeste paulista. Alfa, São Paulo, v. 52, n. 2, 2008. (no prelo) TEIXEIRA, J. Riqueza da língua. Revista Veja, edição 2025, 12 set. 2007. 
VIEGAS, M do C. Alçamento das vogais médias pretônicas: uma abordagem sociolinguística. 231f. 1987. Dissertação (Mestrado em Linguística) Universidade Federal de Minas Gerais, Belo Horizonte, 1987.

VOLPATO, C. Q língua eh essa? Revista da Cultura. Disponível em: <http://www2.livrariacultura.com.br/>. Acesso em: 13 set. 2007.

Recebido em 25/01/09. Aprovado em 15/07/09.

Title: Considerations on the concept of "internetês" in language studies

Author: Fabiana Komesu; Luciani Tenani

Abstract: Our objective in this essay is to discuss the concept of "internetês", popularly known as the written (typed) Portuguese used on the Internet. Based on the perspective of language studies, particularly on theories from discourse studies, we raise questions and to present hypotheses concerning this phenomenon, usually seen as a type of "phonetized" writing or as the "interference of speech on writing". From our point of view, the analysis of "internetês" can enable us to observe a possibility of language and discourse, considering heterogeneity as a constituent trace of language and of verbal human activities. Based on a corpus of written utterances characterized by the use of "internetês", we attempt to demonstrate the relevance of the definitions of writing and language to conceptualize "internetês", taking into account the radical relationship between language and social life.

Keywords: writing acquisition; literacy; orality; discourse; internet.

Titre: Considérations sur le concept de "internetês" dans les études du langage

Auteur: Fabiana Komesu; Luciani Tenani

Résumé: Dans cet essai notre objectif est celui de discuter le concept appelé "internetês", communément connu comme le portugais écrit (digitado) sur internet. De la perspective des études du langage, en particulier, des théories originaires des études du discours, nous cherchons à expliciter des questions et présenter des hypothèses sur ce phénomène qui émerge, ordinairement pris comme écriture "phonétisée" ou comme "interférence du parler dans l'écriture". Selon notre point de vue, analyser l"'internetês" permet d'observer une possibilité de la langue et du discours, en considérant l'hétérogénéité comme trait constitutif du langage et des activités verbales humaines. Ayant comme base, donc, un ensemble de données composé par des énoncés écrits, lesquels seraient caractéristiques de l'“internetês", nous cherchons à démontrer la pertinence des définitions de l'écrit, de langue et du langage pour son conceptualisation, tenant compte de la relation radicale entre langage et vie sociale.

Mots-clés: acquisition de l'ecrit; alphabétisation; oralité; discours; internet.

Título: Consideraciones sobre el concepto de "internetés" en los estudios del lenguaje

Autor: Fabiana Komesu; Luciani Tenani

KOMESU; TENANI - Considerações sobre o conceito de "internetês"... 
Resumen: Nuestro objetivo en este ensayo es discutir el concepto del llamado "internetés", popularmente conocido como el portugués escrito (digitado) en la Internet. De la perspectiva de los estudios del lenguaje, en particular, de teorías provenientes de los estudios del discurso, buscamos explicitar preguntas y presentar hipótesis acerca de ese fenómeno en emergencia, comúnmente tomado como escritura "fonetizada" o como "interferencia del habla en la escritura". Desde nuestro punto de vista, analizar el internetés permite observar una posibilidad de la lengua y del discurso, considerándose la heterogeneidad como rasgo constitutivo del lenguaje y de las actividades verbales humanas. Con base, pues, en un conjunto de datos compuesto de enunciados escritos, los cuales serían característicos del internetés, buscamos mostrar la relevancia de las definiciones de escrita, de lengua y de lenguaje para su conceptuación, llevando en cuenta la relación radical entre lenguaje y vida social.

Palabras-clave: adquisición de la escritura; letramiento; oralidad; discurso; Internet. 